\title{
Observations of the performance of the U.S. Laboratory Architecture
}

\author{
Rod Jones \\ National Aeronautics and Space Administration, Lyndon B. Johnson Space Center
}

\begin{abstract}
The United States Laboratory Module "Destiny" was the product of many architectural, technology, manufacturing, schedule and cost constraints which spanned 15 years. Requirements for the Space Station pressurized elements were developed and baselined in the mid to late ' 80 's. Although the station program went through several design changes the fundamental requirements that drove the architecture did not change. Manufacturing of the U.S. Laboratory began in the early 90's. Final assembly and checkout testing completed in December of 2000. Destiny was launched, mated to the International Space Station and successfully activated on the STS-98 mission in February of 2001. The purpose of this paper is to identify key requirements, which directly or indirectly established the architecture of the U.S. Laboratory. Provide an overview of how that architecture affected the manufacture, assembly, test, and activation of the module on-orbit. And finally, through observations made during the last year of operation, provide considerations in the development of future requirements and mission integration controls for space habitats.
\end{abstract}

\section{ARCHITECTURE AND REQUIREMENTS}

In normal building construction the product of "architecture" are the drawings and specifications, which identify hardware requirements and depict the integrated design. In the Space Station program the "architecture" was established through the specification of key hardware features and constraints. These features imparted an inherent capability that was used to help manufacture, assemble, test and activate the hardware.

The original requirements were established early in the development phase of the Space Station program. SAE paper "Early Decisions for Space
Station " 2000-01-2329 described the requirements selection process used to define the quadrant or four post architecture of the Space Station pressurized elements. The key features where the pressure vessel envelope, standoffs, racks and hatch shape and size.

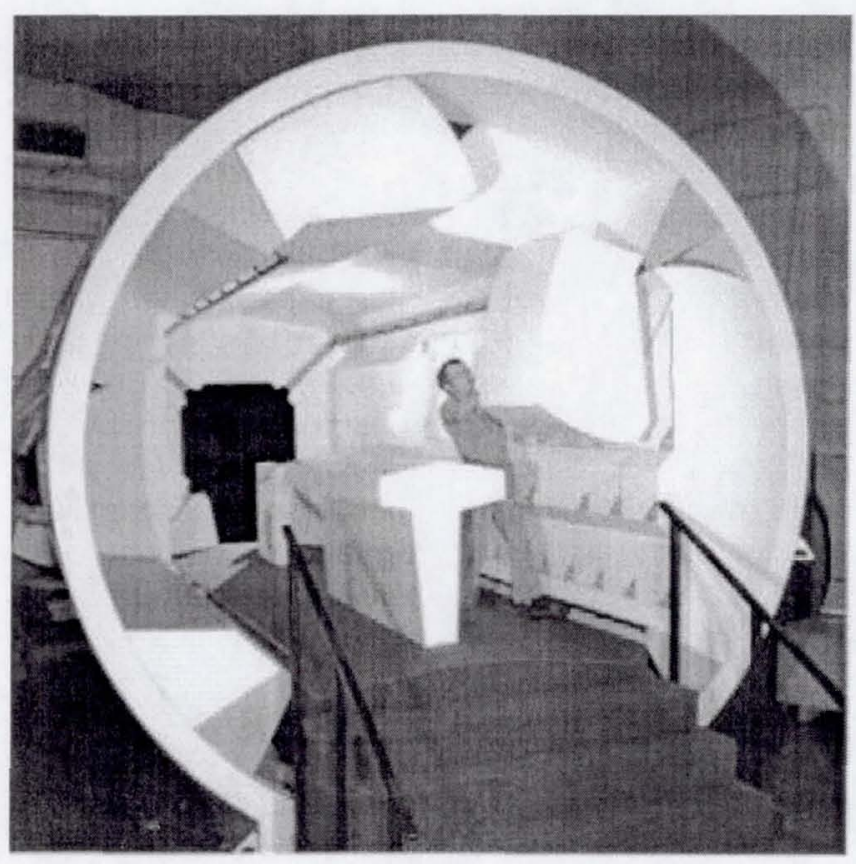

Don Magargee demonstrating the 1985 McDonnell Douglas proposed quadrant design 


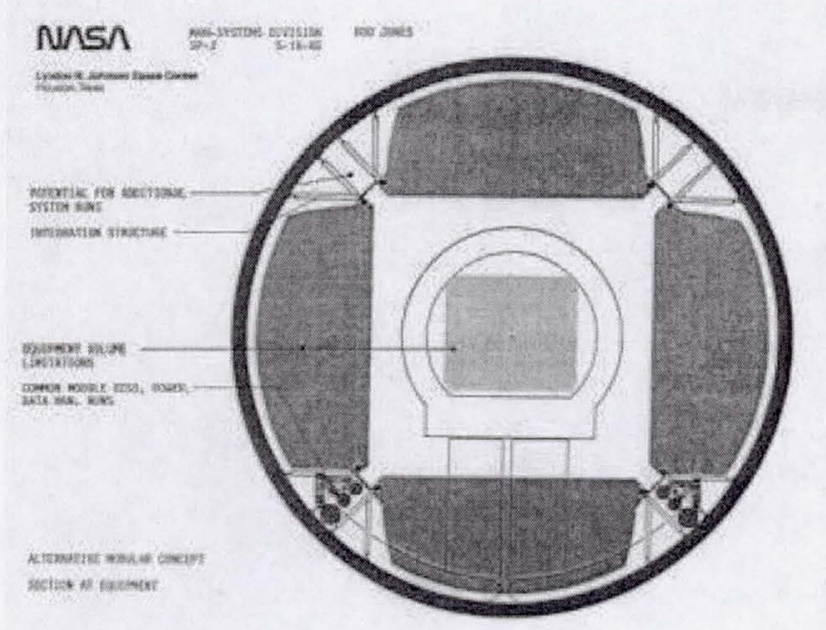

NASA 1985 Crew Station Review No.2 sketch depicting key architectural features for the four standoff concept

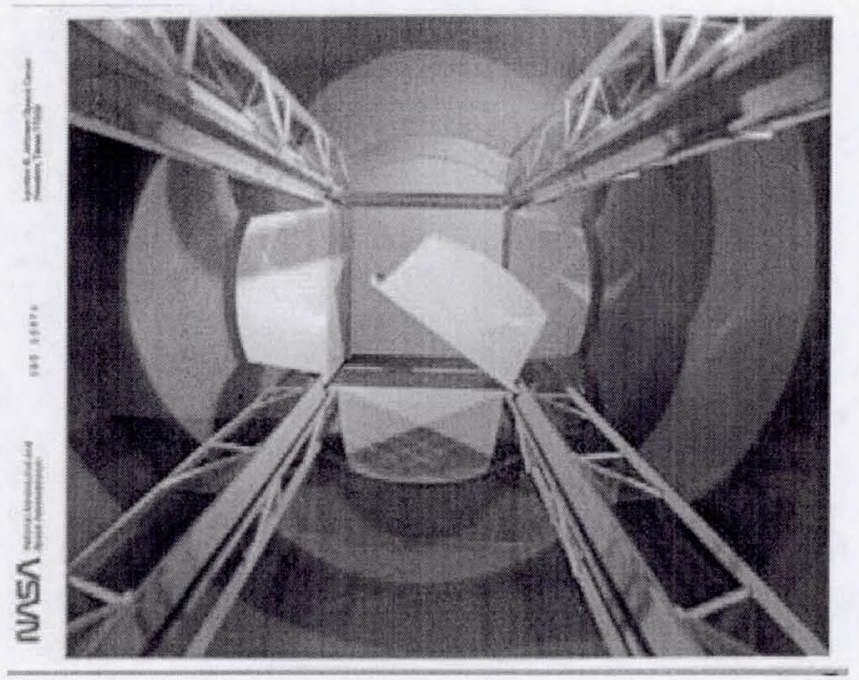

Early model depicting standoff and rack architecture and depicting rack rotation

Module: The size of the modules was dictated by the cargo bay capacity of the Space Shuttle. As defined by the International Space Station Interface Definition Document NSTS-21000-IDD-ISS, the maximum dynamic envelope diameter of the module is 180 inches. Once the primary structure was completed it was installed in the element rotation stand. It was supported through the launch longerons and trunions that were eventually used to secure the module in the cargo bay for launch. This stand allowed the module to be rotated 360 degrees. Rotating the module facilitated access to the external and internal surfaces during assembly.

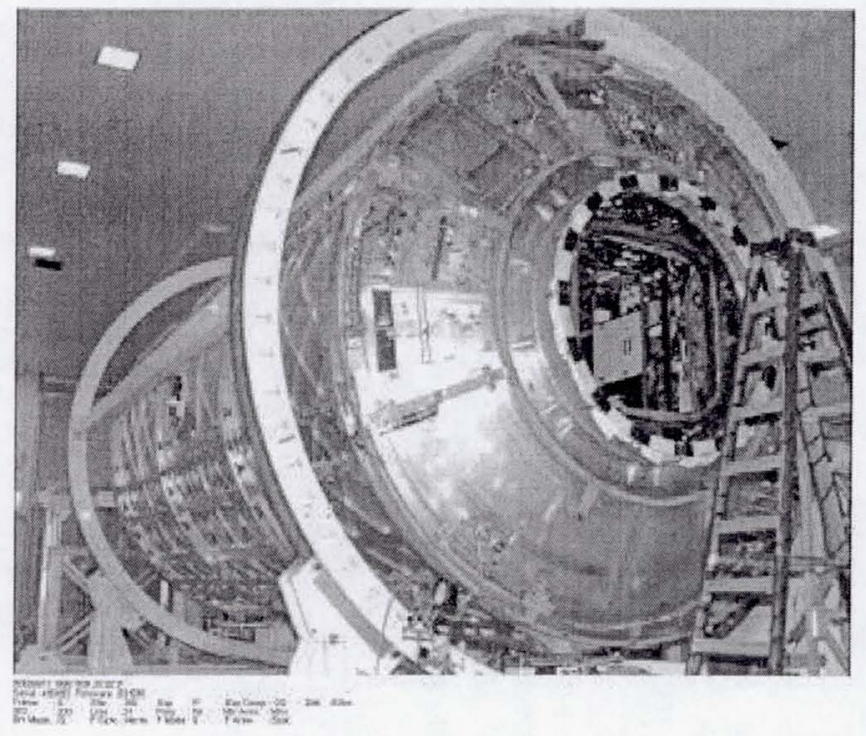

External view of the Destiny module installed in the Element Rotation Stand prior to installation of multi layer insulation and meteor debris shields

Standoffs: The standoffs were defined as the areas for structure to support the distribution of utilities, attach core hardware such as lights and vents, and to provide on-orbit attachment points for racks. In order to allow the various teams of technicians to work simultaneously they were assembled outside of the module.

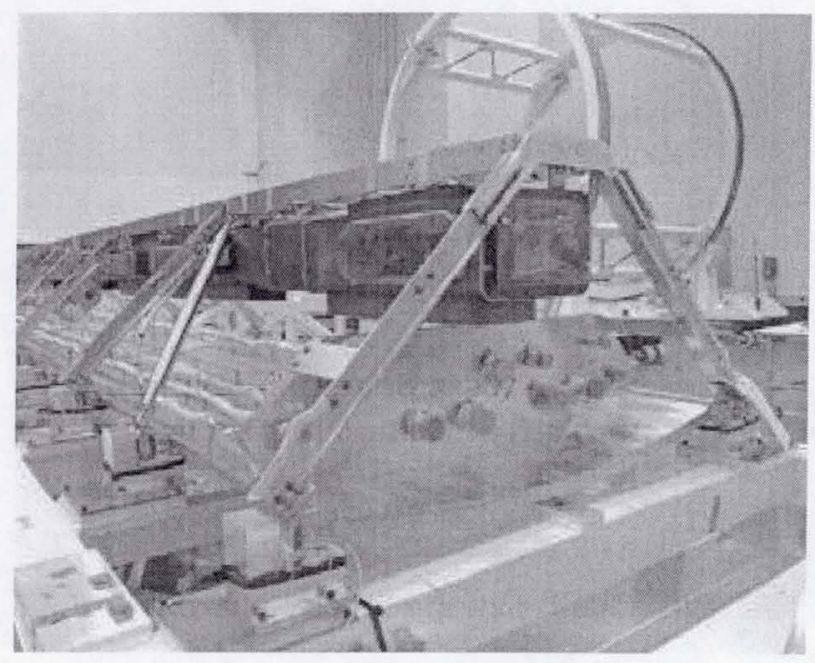

\section{Destiny module standoff during assembly}

Each standoff was a self-contained element. This allowed power and fiber optic harnesses, hoses and vacuum lines to be tested and verified while there was adequate accessibility. Once assembly and testing was complete the standoffs were inserted into the module, suspended from a rail that 
passed through both ends of the module, and lowered into place

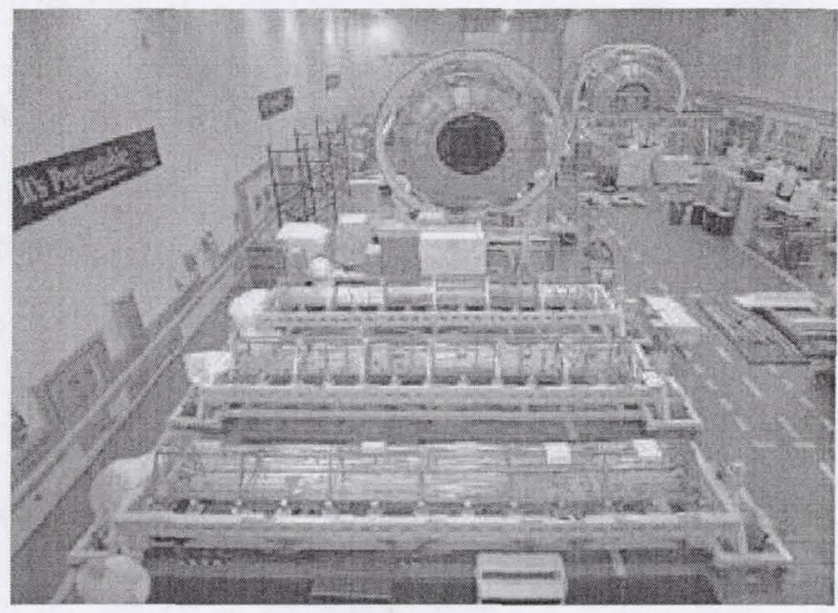

Destiny standoffs (foreground) and module (background) during early assembly

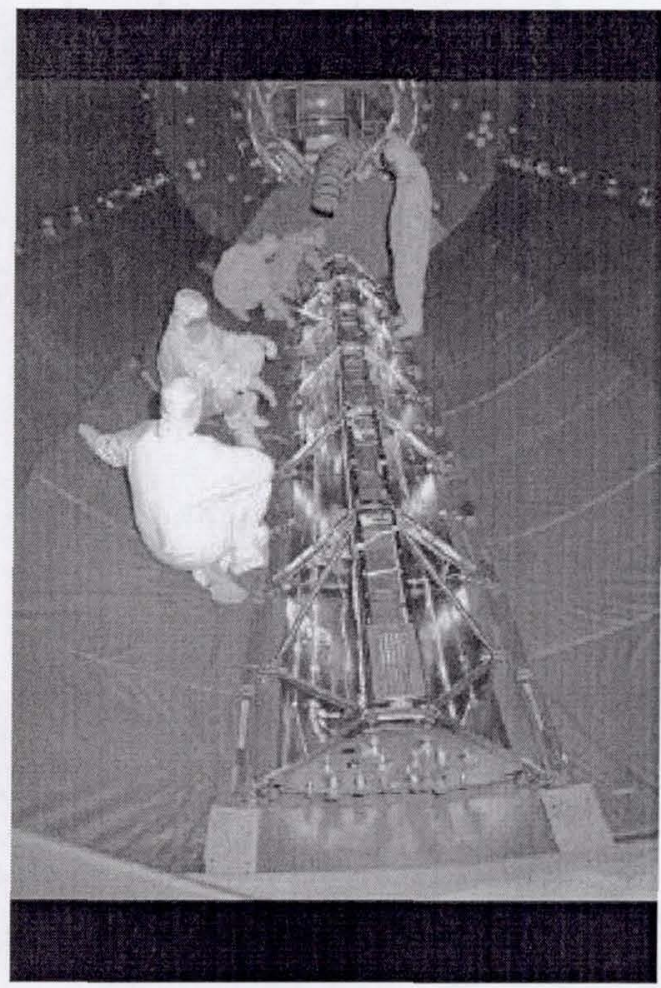

Installation of the first standoff into the module

Endcone area: The endcones of the module provide a zone for the subsystem distribution lines and cables to transition from the standoffs to the hatch to feed though to the next module. The use of the endcone areas was not specified. Although the requirements required system designers to package hardware into the racks the endcone's afforded valuable outfitting space that could not be wasted. Consequently several major subsystem components were located in this area including data management mass memory units, power system controllers, and emergency response equipment including portable fire extinguishers and portable breathing masks. All hardware layouts had to conform to the same accessibility requirements for maintenance and change out. Unlike the standoffs and racks the endcone's had to be outfitted inside the module therefore assembly and test of this area was in the critical path to completing the module.

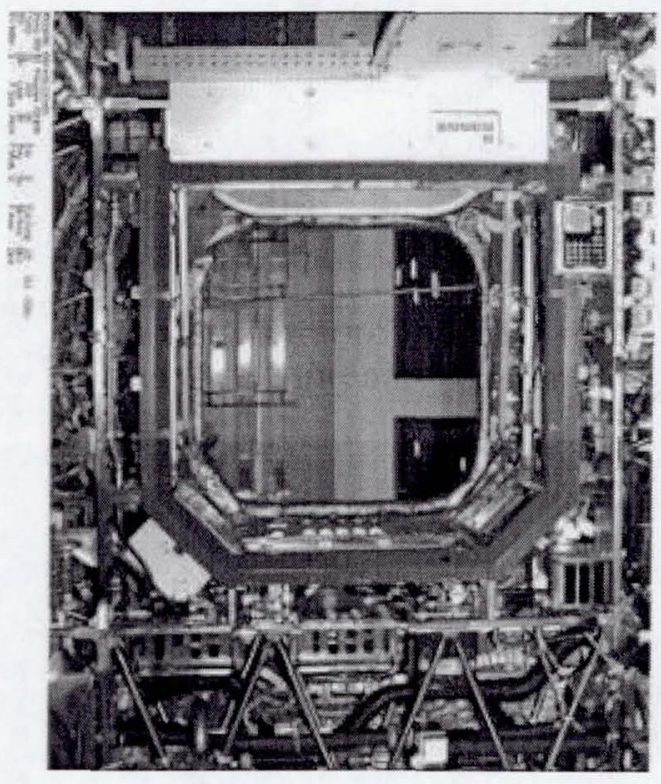

\section{Endcone outfitting prior to closeout installation}

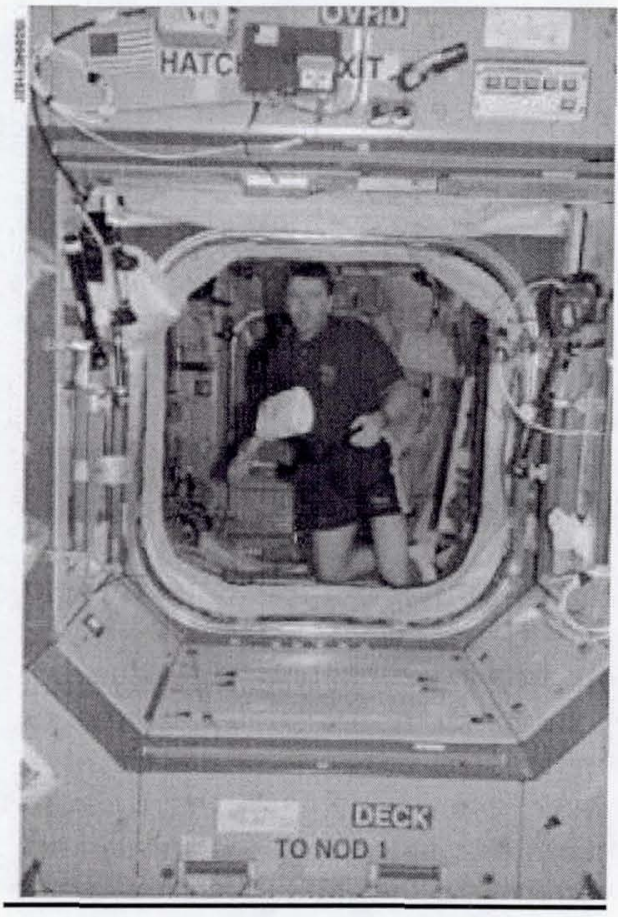

Endcone with closeouts in place 
Racks: Racks were defined as the primary method of hardware system and payload packaging for onorbit change out. Similar to the standoffs this allowed for the independent assembly and checkout of each rack prior to installation in the module. This enabled a significant portion of the sub systems be integrated in parallel.

Rack level packaging allowed the program to respond to significant requirements changes without having to redesign the entire module. In the Freedom program the baseline requirement was to orbit the space station at a low inclination. When Russia joined the ISS program the stations inclination was raised to 51.6 degrees. This inclination significantly reduced the amount of cargo the Shuttle can carry on any one mission. The Lab manufacturer was able to minimize the impact from this change by off loading non-essential racks. The off loaded racks were carried to orbit on subsequent missions in the Multi Purpose Logistics Module (MPLM).

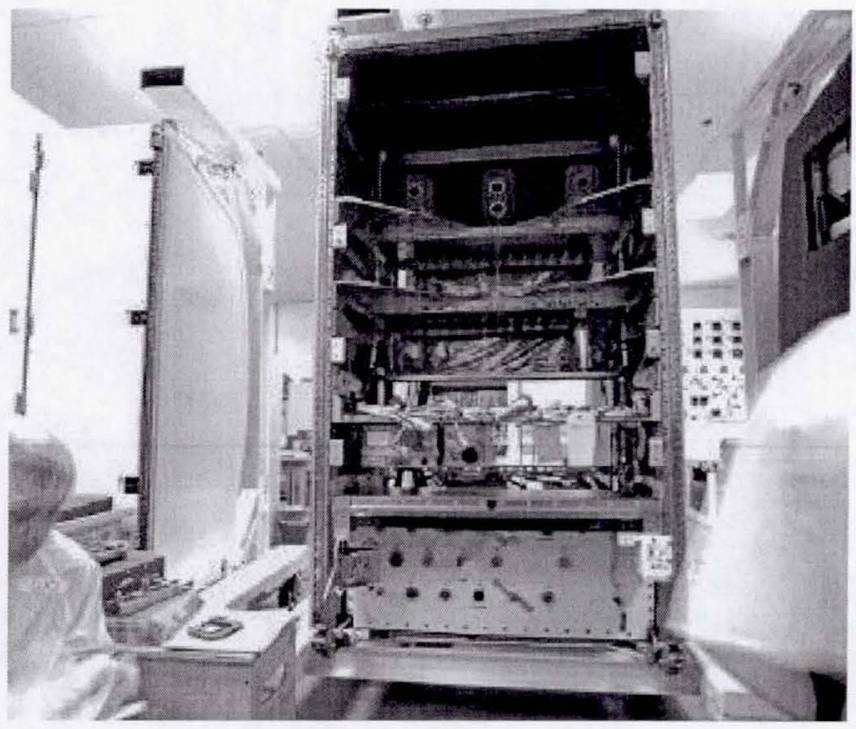

Equipment Rack during assembly

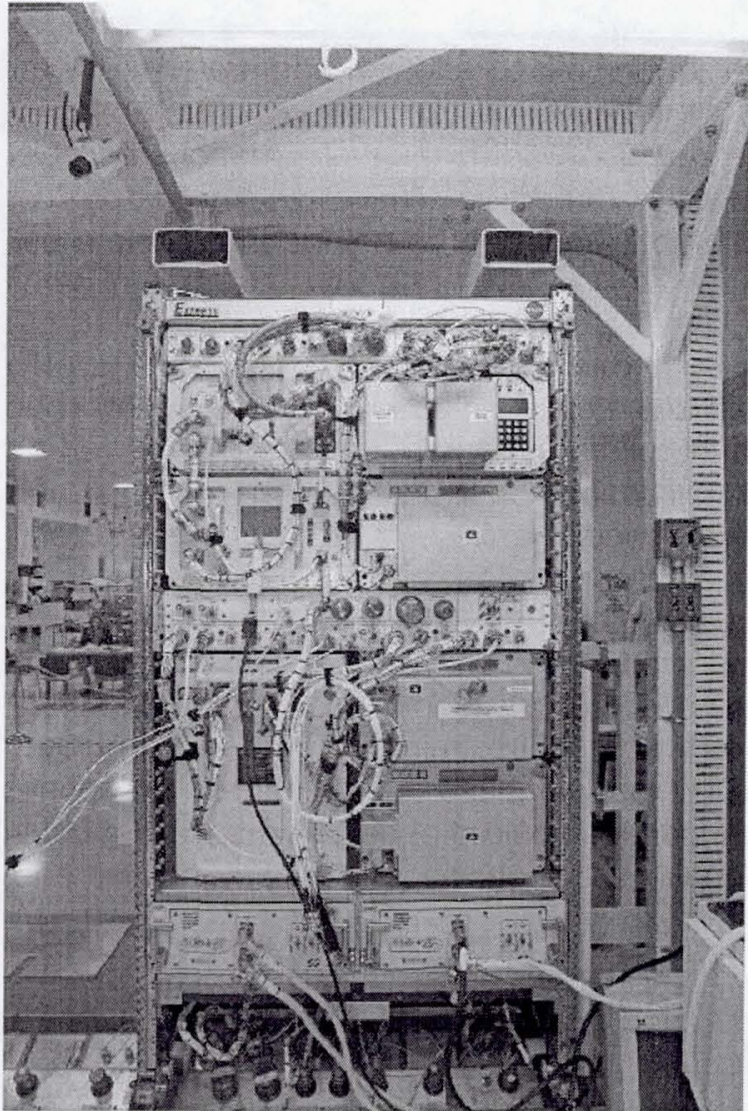

\section{Payload EXPRESS Rack during standalone checkout testing}

Racks were installed and removed numerous times during the test phase of the program in order to resolve anomalies or replace failed components.

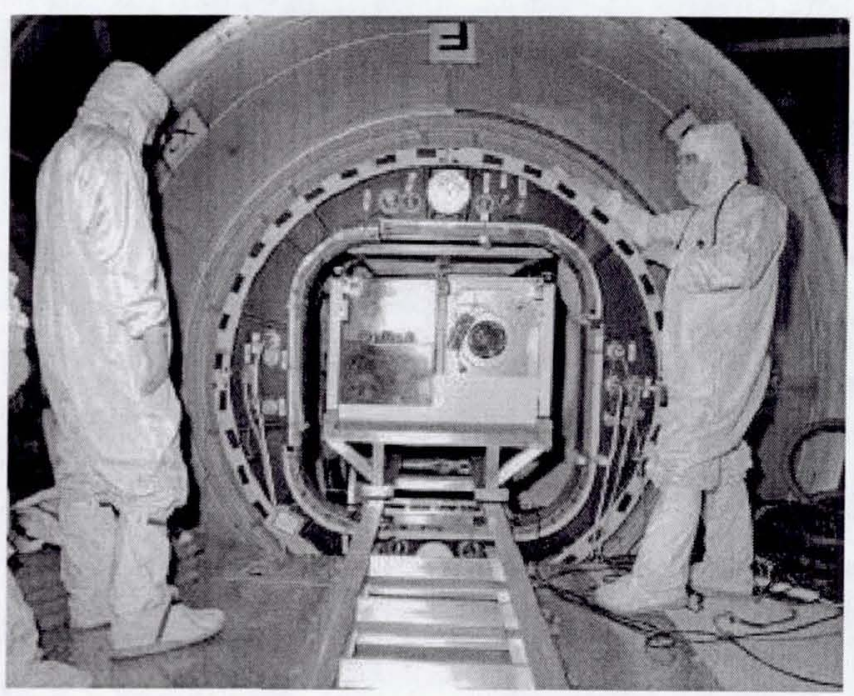

Rack being installed in the module

Hatches: The hatch was sized to accommodate the on-orbit transfer of racks, cargo and crew. Special ground handling equipment is required to 
pass racks through the hatch and install them on the ground. Due to the tight tolerances between the hatch and the rack a dolly and track system is used to pass the rack through the hatch for module outfitting. The Multi Purpose Logistic Module (MPLM) employees a large aft access hatch which in only operable on the ground. The large opening provides greater clearance between the rack and the hatch and allows the use of specialized boom crane named the Rack Insertion Device.

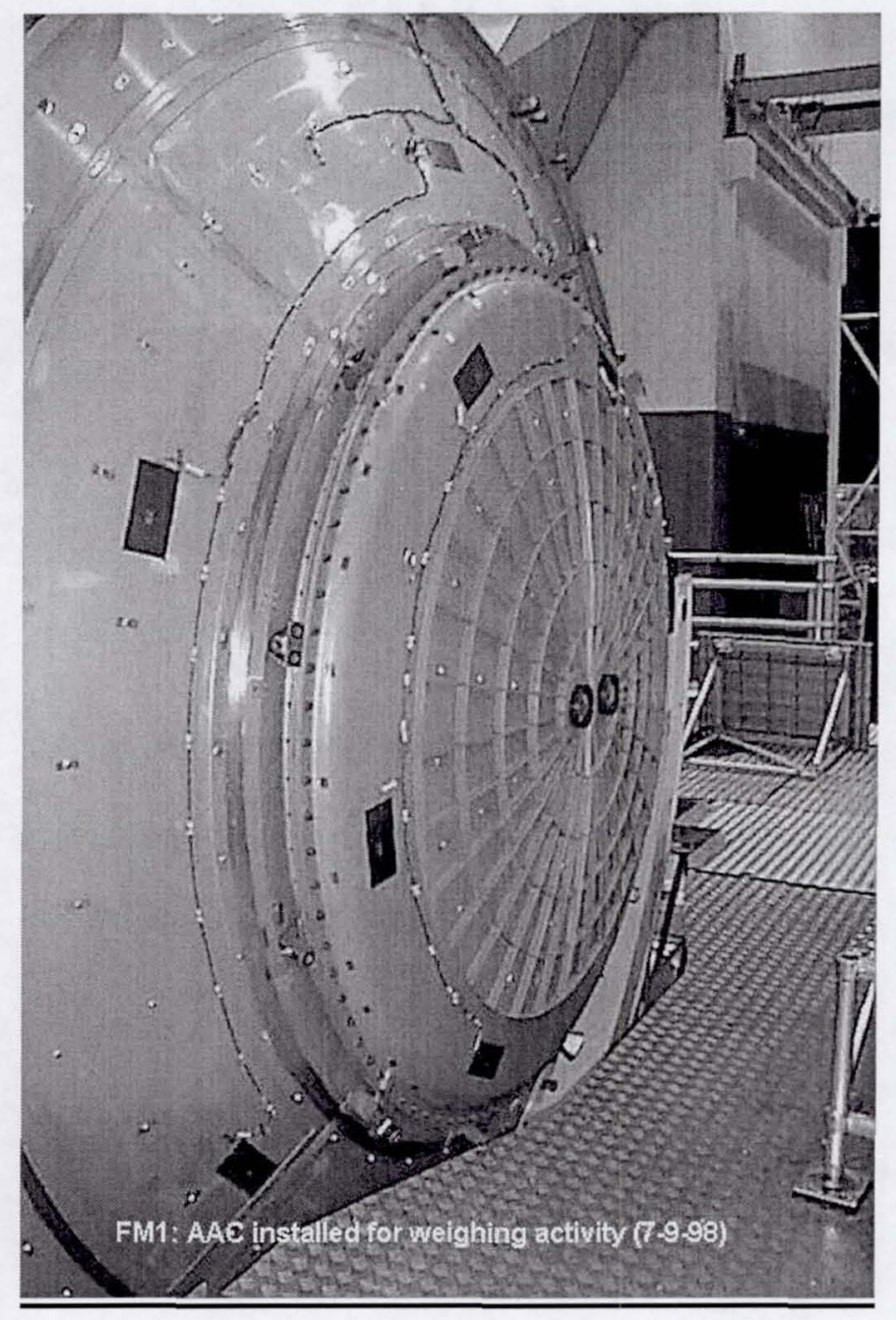

\section{MPLM Aft Access Closure}

Stowage: The original primary resupply and orbit stowage unit was the Resupply Stowage Rack (RSR). This was a hard walled locker system where each locker is designed to protect its contents from the rest of the cargo in the rack. Although cargo friendly the weight of the rack is close its cargo carrying capability.

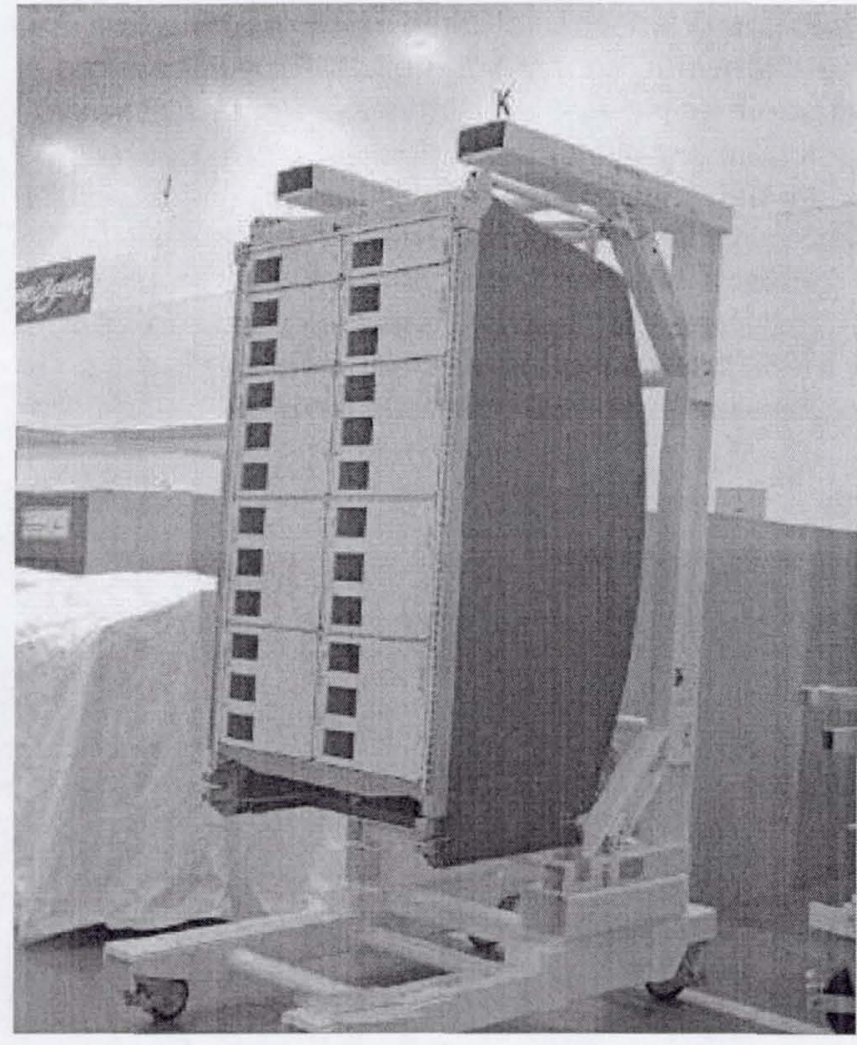

\section{Resupply Stowage Rack attached to ground support equipment}

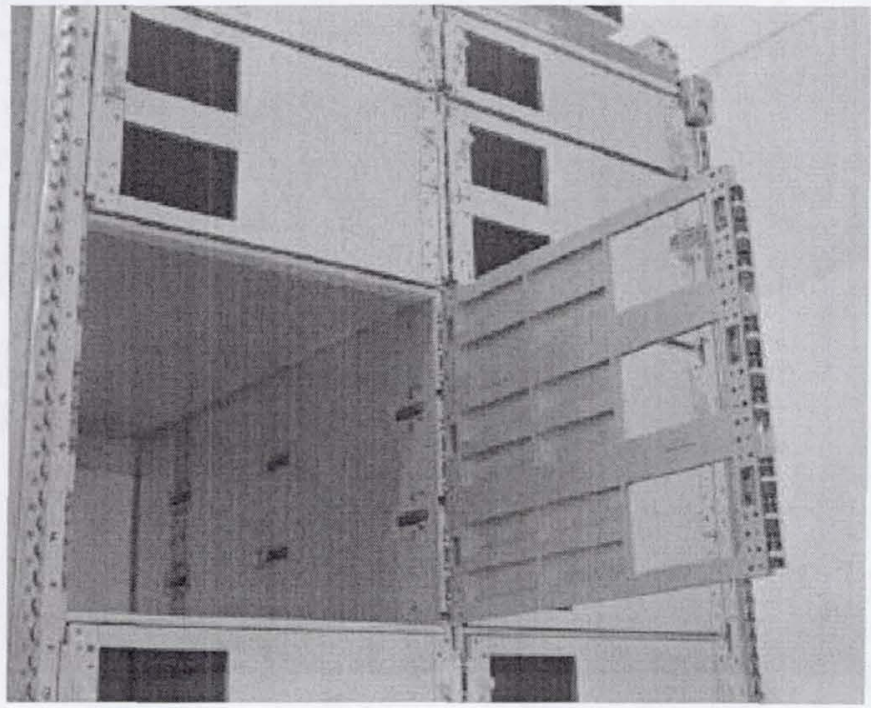

\section{Stowage Locker}

In order to save weight and to provide additional stowage on-orbit the program developed a Zero-g Stowage Rack (ZSR). This fabric rack could be launched in the empty rack bays in the module and deployed to hold cargo on-orbit. 


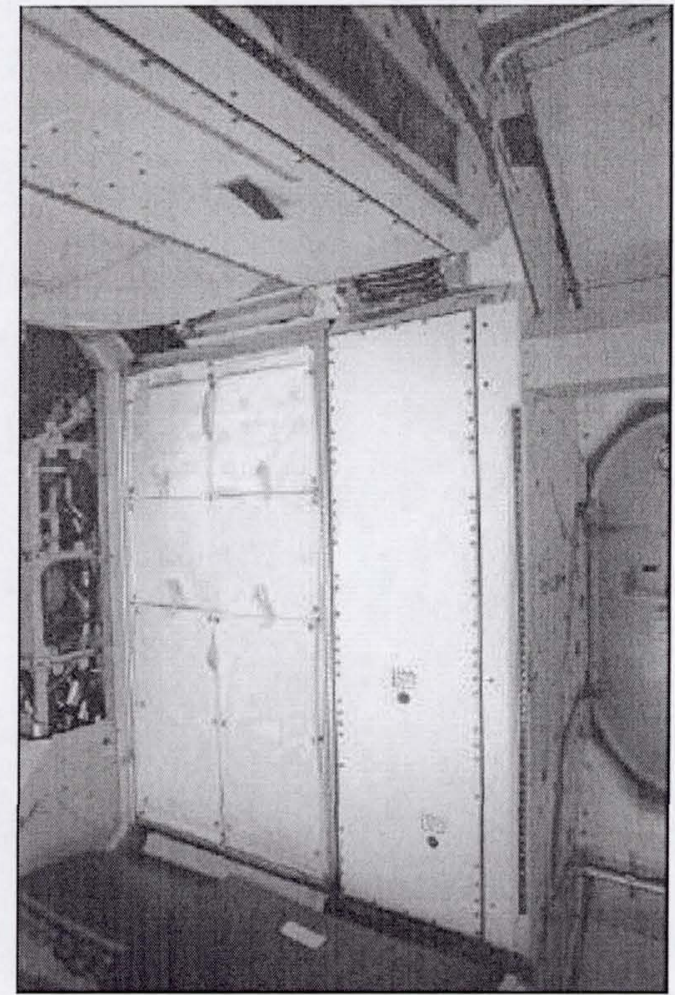

\section{ZSR installed in the Unity Node}

Resupply Stowage Platform (RSP) was developed with the desire to reduce the weight of the structure there by allowing more mass to be allocated to the cargo. The RSP consists of a center plate with attach point allowing bagged cargo to be strapped to both sides. Although the rack weight is significantly reduced the bags provide less cargo protection than the RSR lockers so more padding is required reducing the volumetric efficiency. Each resupply mission is made up of a complement of RSR's and RSP's depending on the cargo requirements.

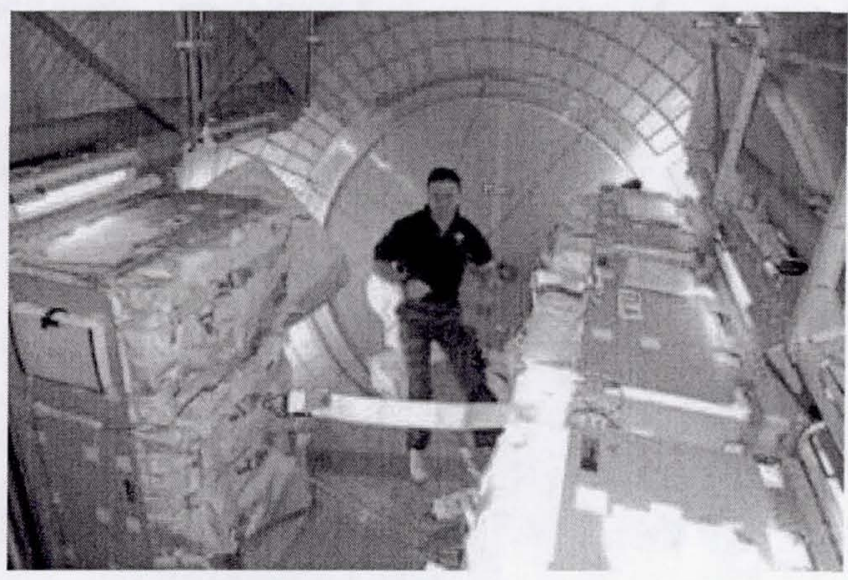

Interior of Multi Purpose Logistics Module onorbit

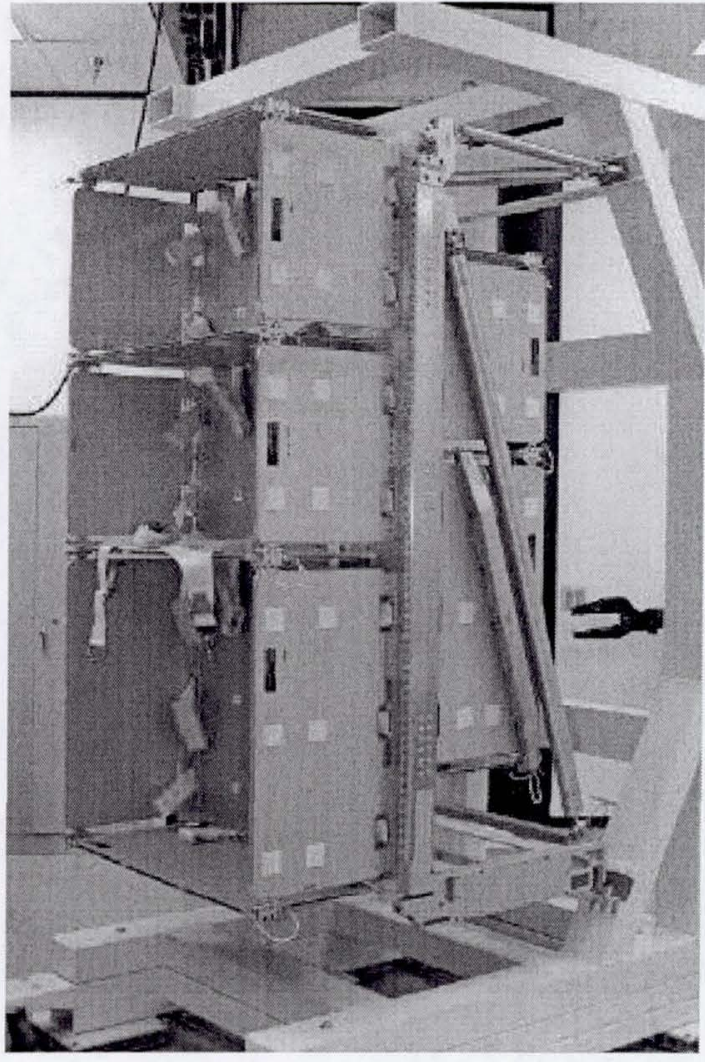

Resupply Stowage Platform

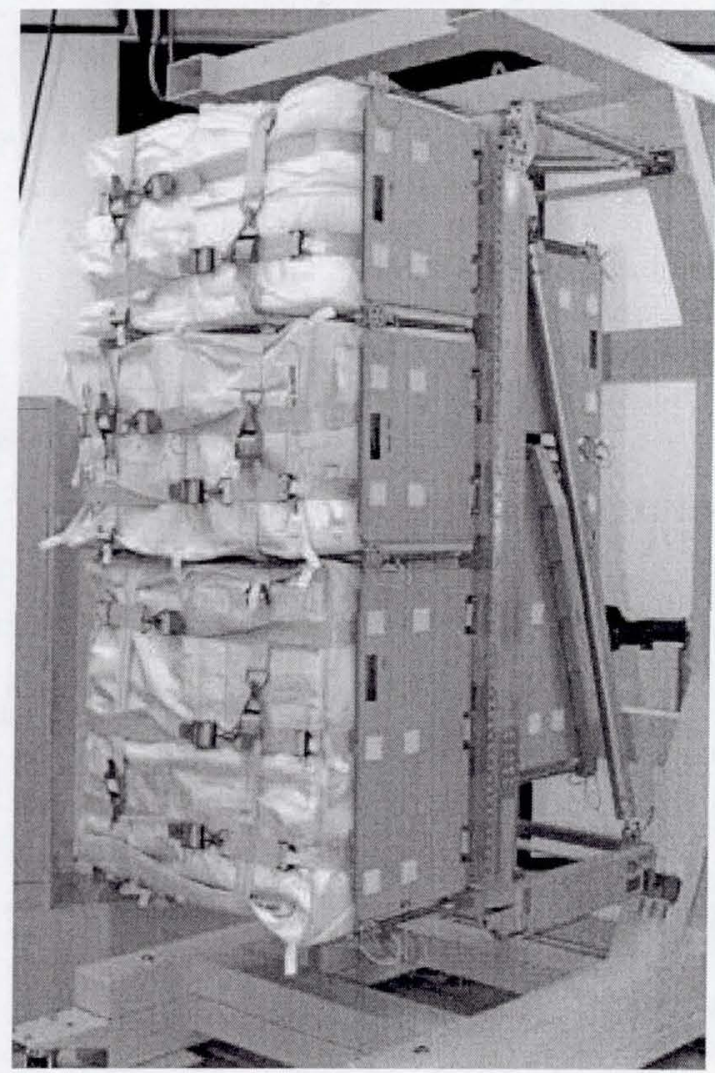

Resupply Stowage Platform packed for a mission 
STS-98 Launch Package 5A Mission: The 5A mission launched in February of 2001 and ended with the successfully installation and activation of the destiny module. The mission went according the plan outlined in SAE paper "Architecture in Mission Integration, Choreographing Constraints" 2000-01.

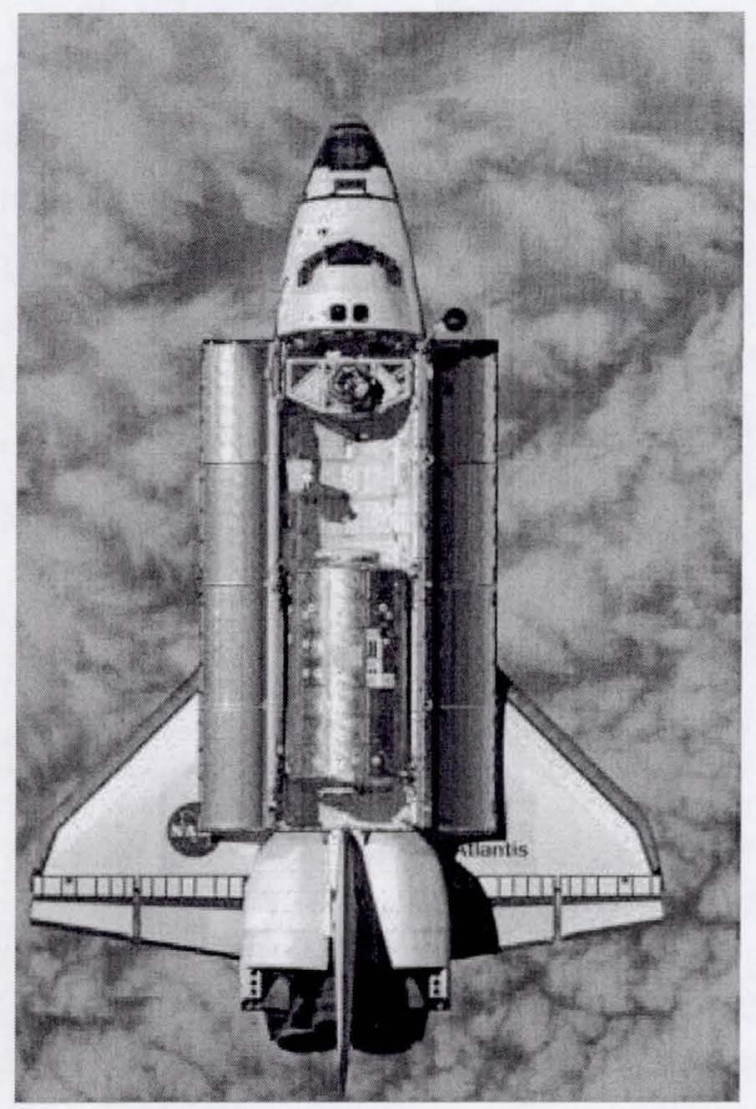

STS-98 with the Destiny module during approach to ISS

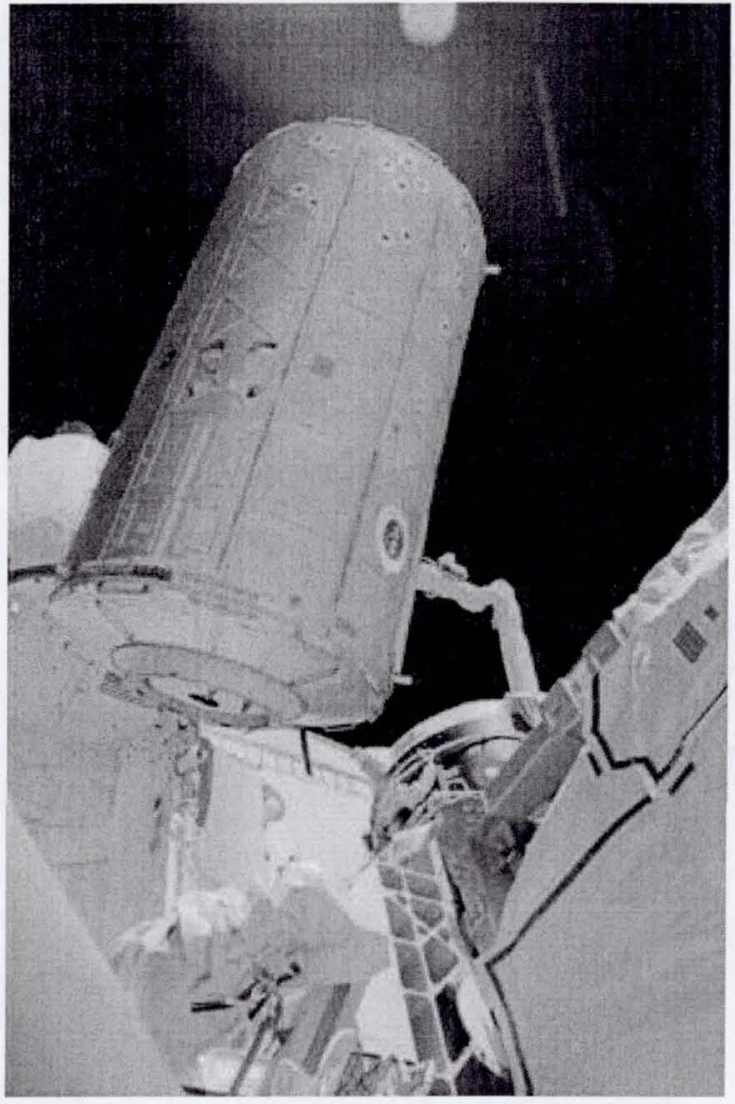

Destiny module being removed from the cargo bay

The Destiny module was launched with 5 system racks, 8 ZSR's, a minimum number of crew restraints and 10 rack front closeout panels. The closeout panels were fabric rack front partitions required to maintain proper aisle airflow

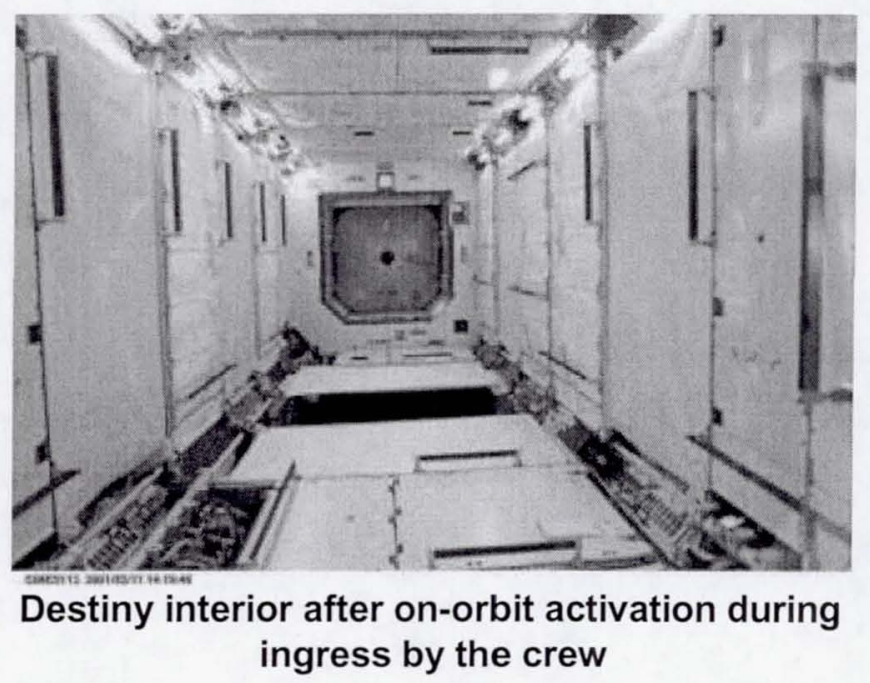

After the module was berthed to the ISS the crew's primary task was the set up and activation of the Lab systems. 


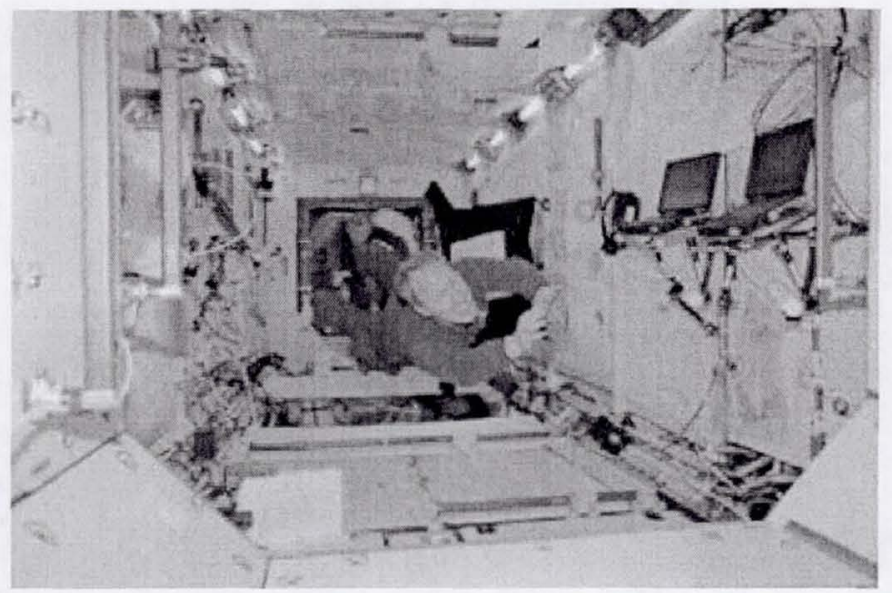

\section{Initial Lab outfitting}

One key task was the relocation of the Atmosphere Revitalization System rack. It was launched in a location that optimized the center of gravity for the module for launch. This required the crew to relocate it on-orbit prior to activation. Although mock-ups depicting various portions of the task had been used to demonstrate the concept it was not possible to simulate end-to-end task.

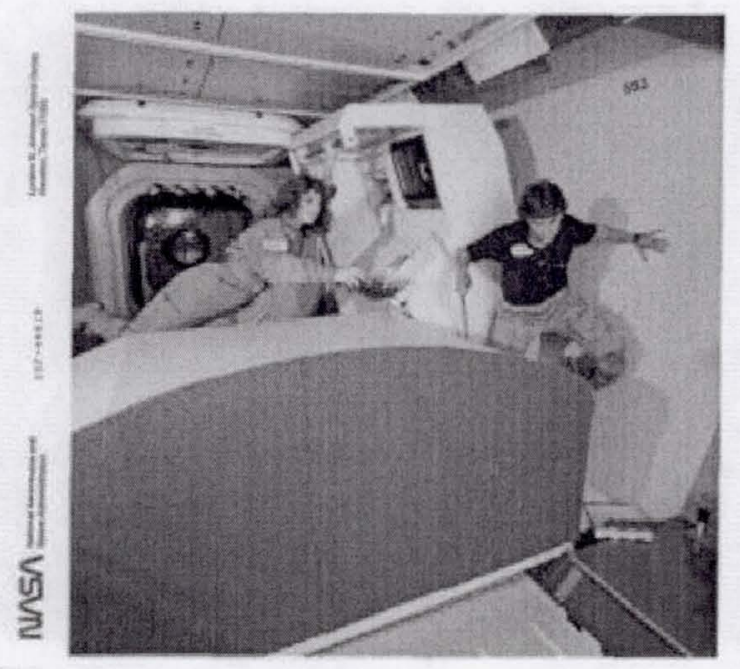

\section{Early mockup demonstration of rack installation}

The crew demonstrated on $5 \mathrm{~A}$ and subsequent outfitting missions have shown that rack transfer and installation is a relative easy job for the crew to perform and does not require the use of specialized handling aids.

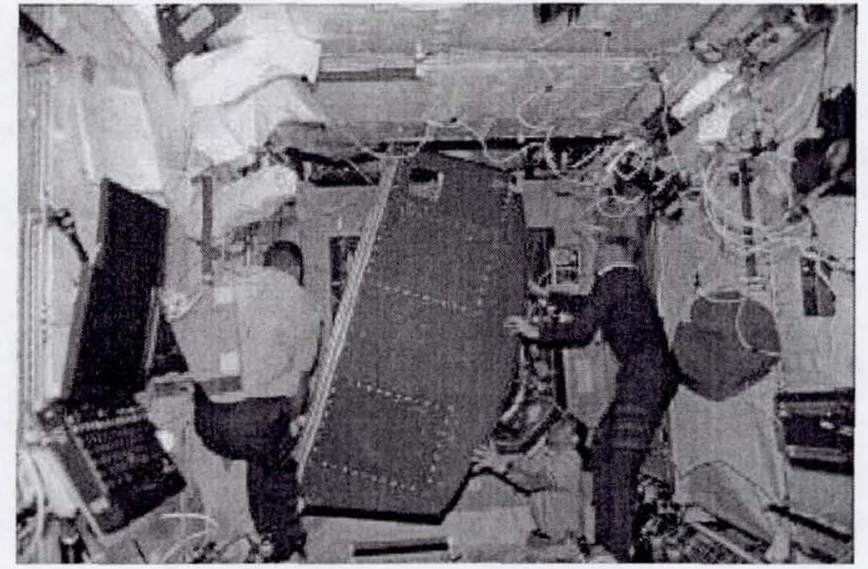

\section{Crewmembers performing the first on-orbit} rack relocation

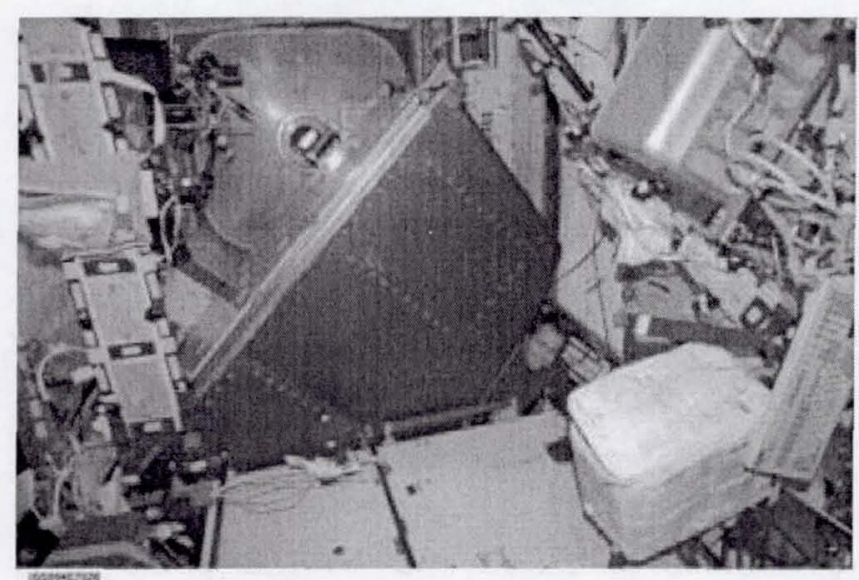

Rack tilted out for standoff maintenance

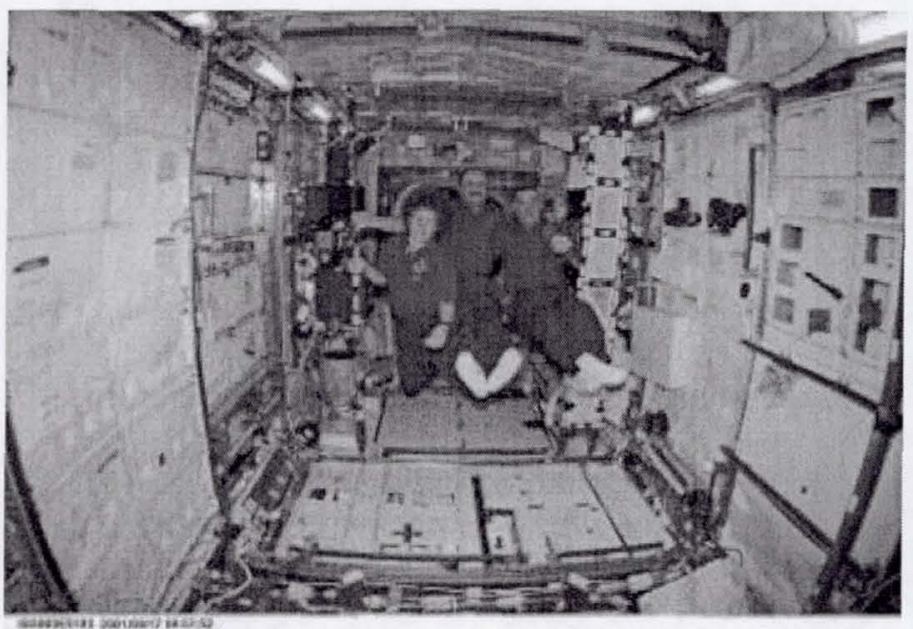

Lab interior during Expedition 


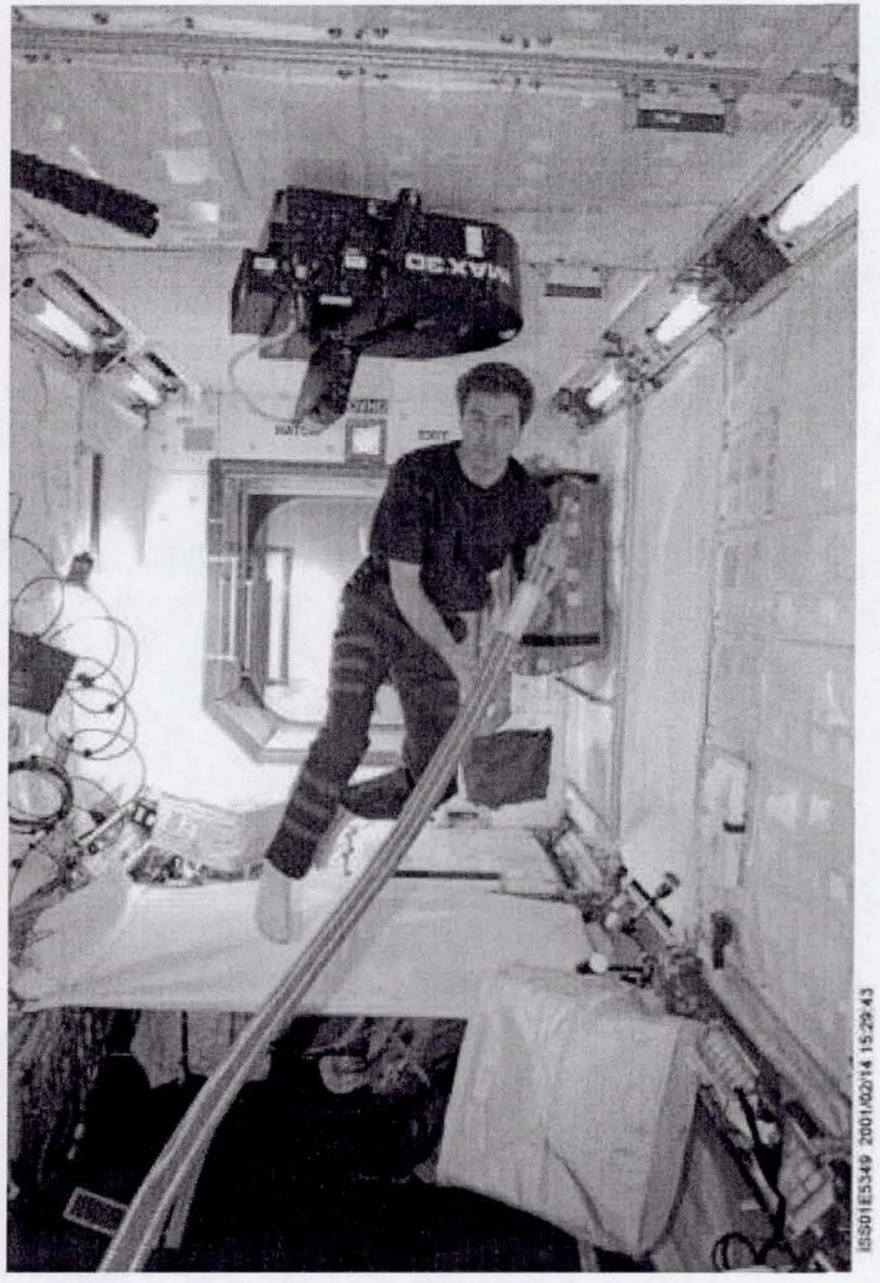

Deployment of a vacuum hose

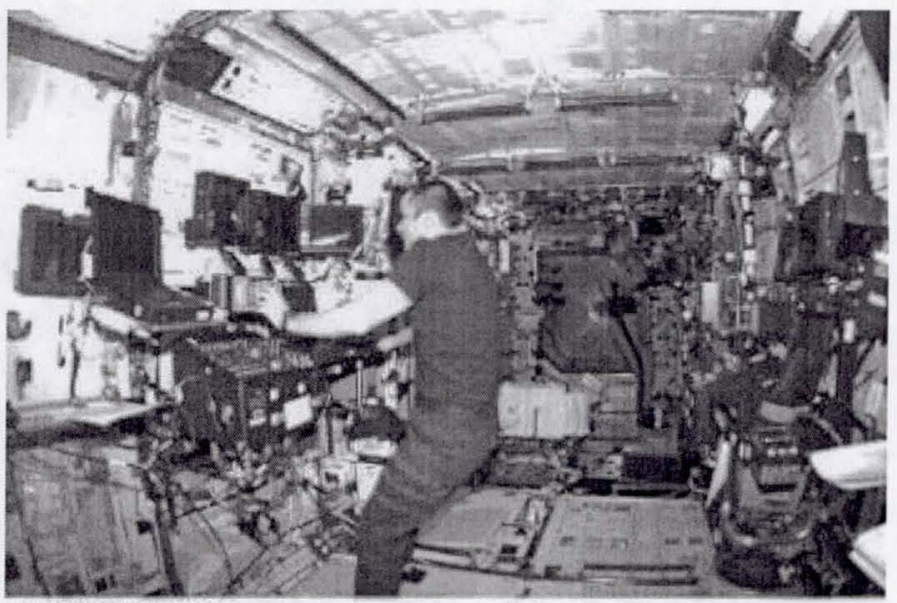

Robotics Workstation
Adapting the environment to meet real life needs: The crew has made numerous on-orbit additions and modification to the environment to suit their particular needs. The following images depict some of those changes.

When the Service Module was launched the table was offloaded because of limited ascent performance. The crew improvised a table from excess flight support equipment.

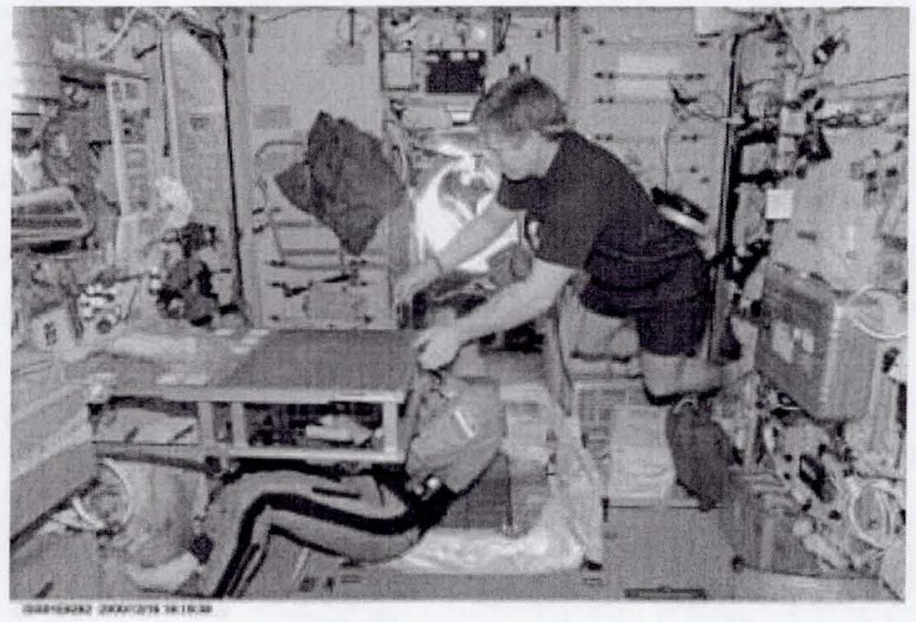

\section{Installation of "Shep's Table"}

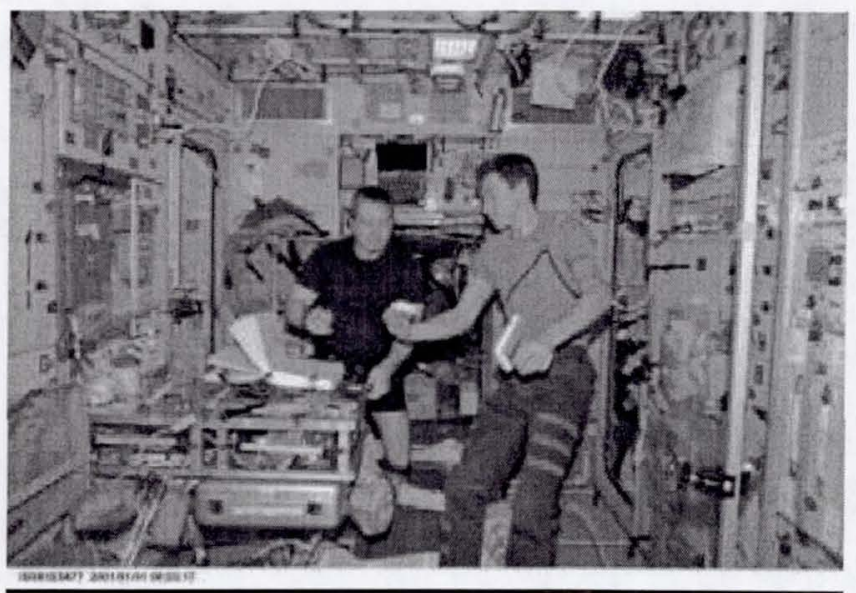

\section{"Shep's" table in use}

The crew added a ships bell to announce and arrival of a new crew to the Station and a ships log to document their visit. 


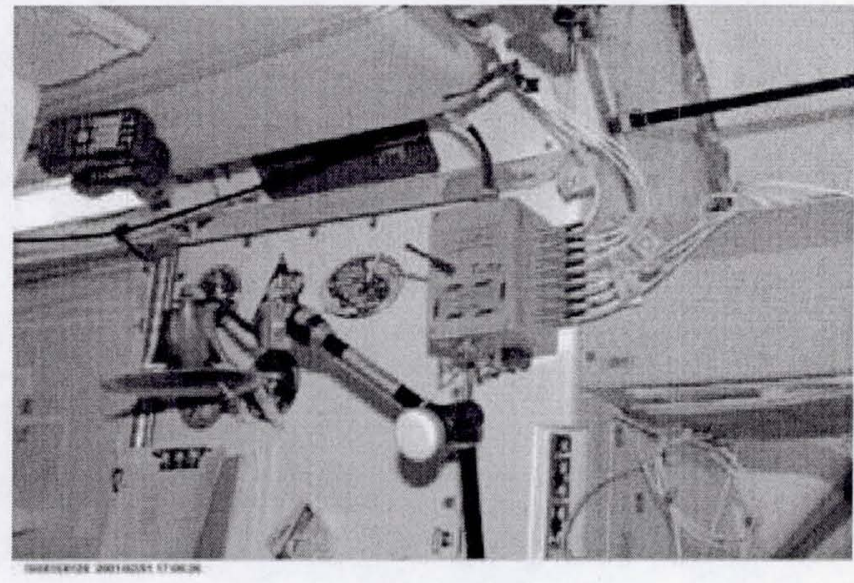

Ships bell

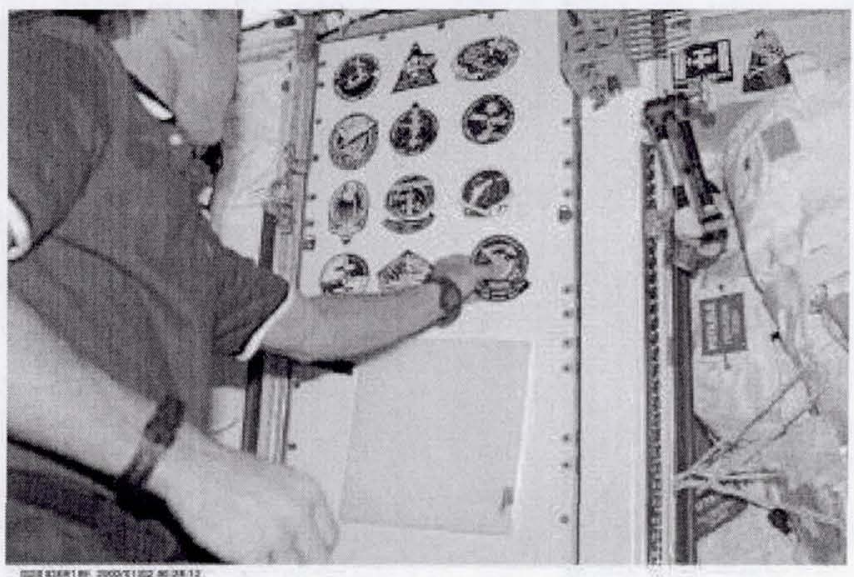

Visiting crews leaving their patch

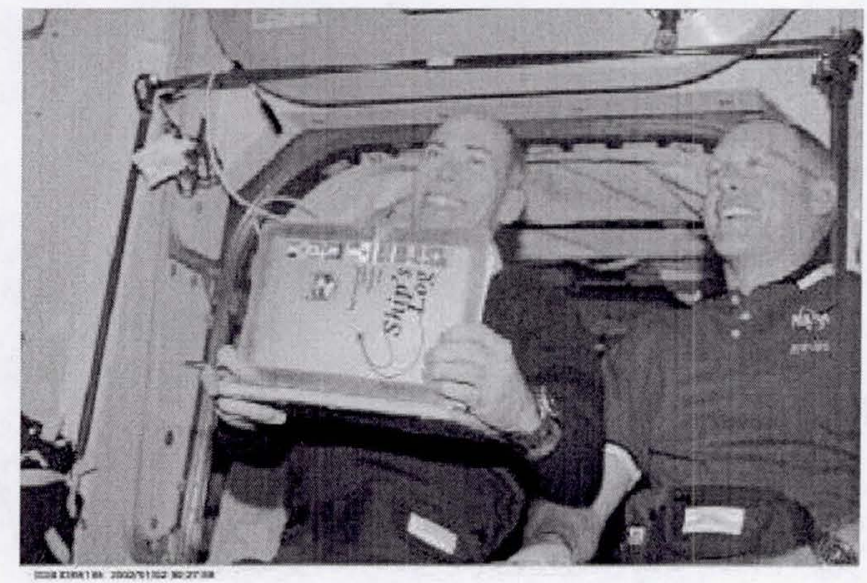

Ships Log

The initial requirements specified that the Russian partners would provide three crew quarters. The Service Module was designed for only two crew. The two program agencies could not come to agreement on the adequate implementation of a third crew quarter on the Russian Segment. The Temporary Sleep Station (TeSS) was developed and installed in the Destiny module. It has many of the key features envisioned for the US habitation module crew quarters including a bump out to provide adequate internal volume, wall mounted sleep restraint, a workstation, and surface to put up personal mementos.
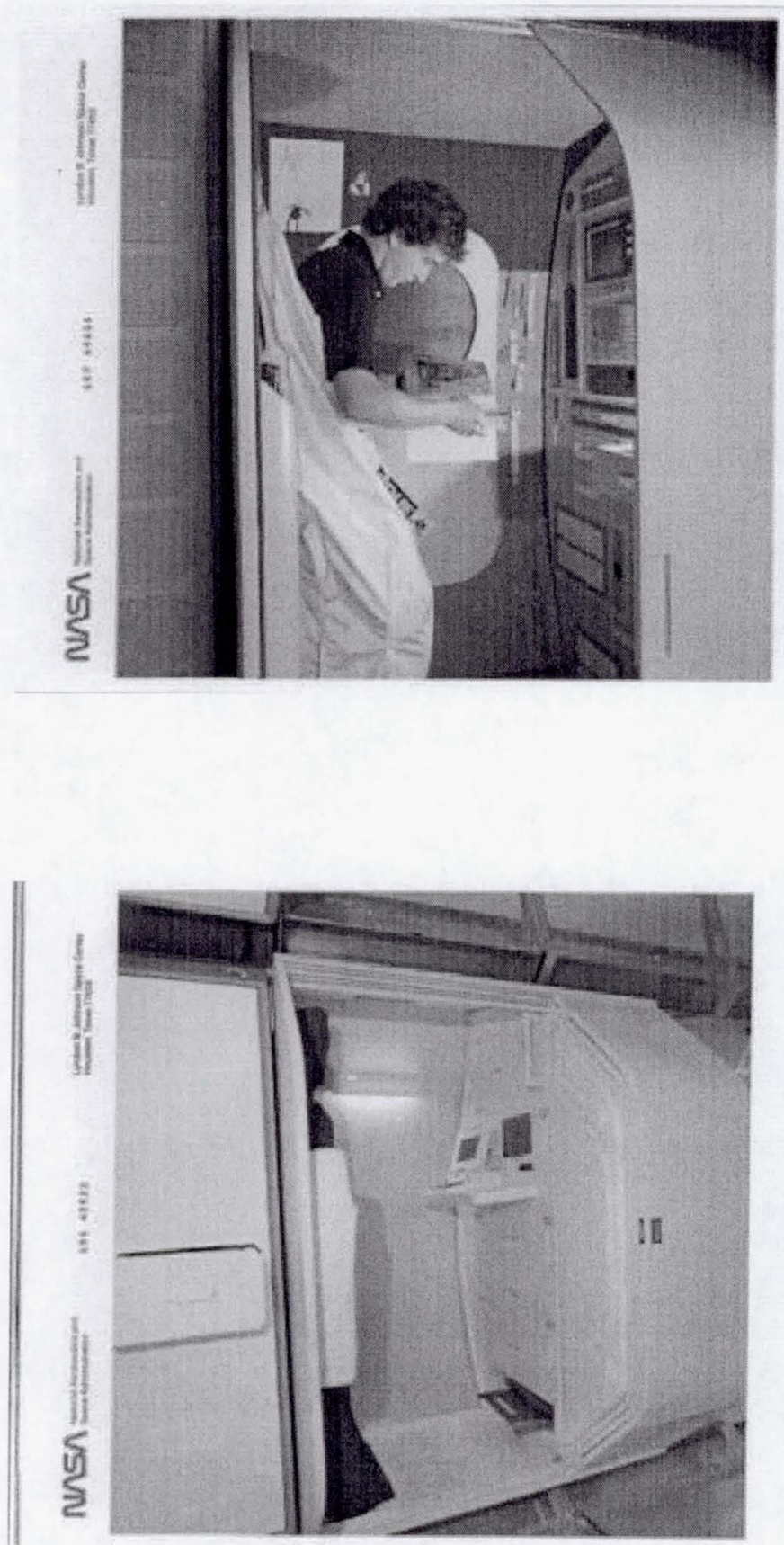

Mock ups of the Habitation module crew quarter concept 


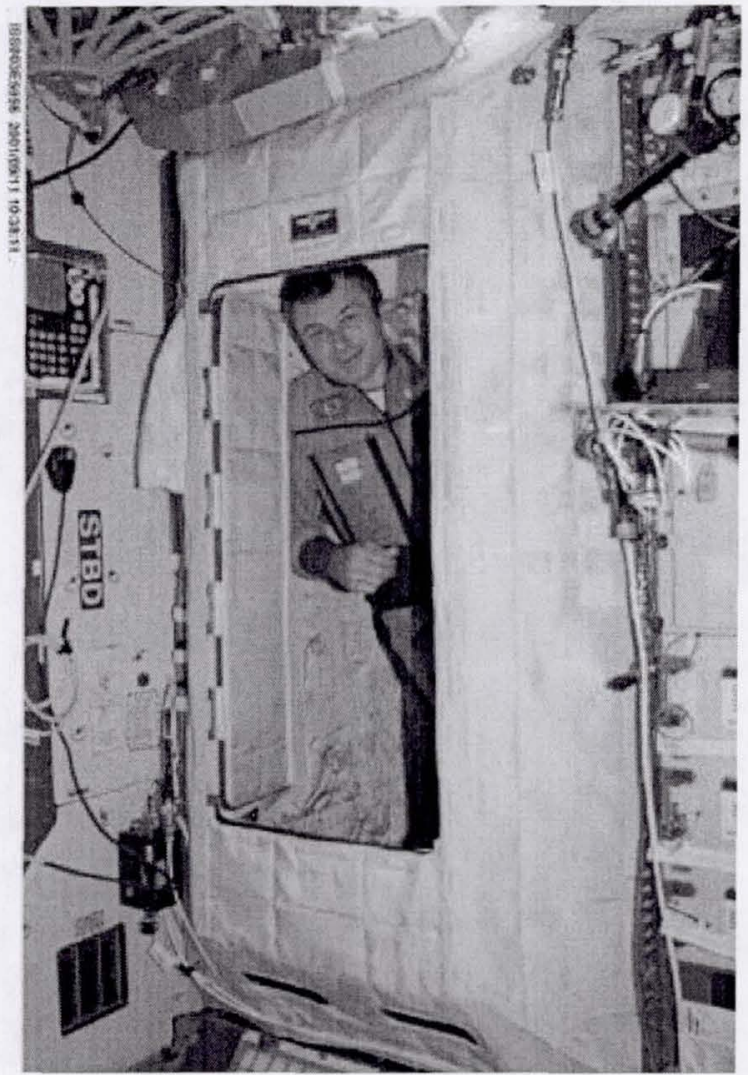

TeSS deployed in the Destiny module

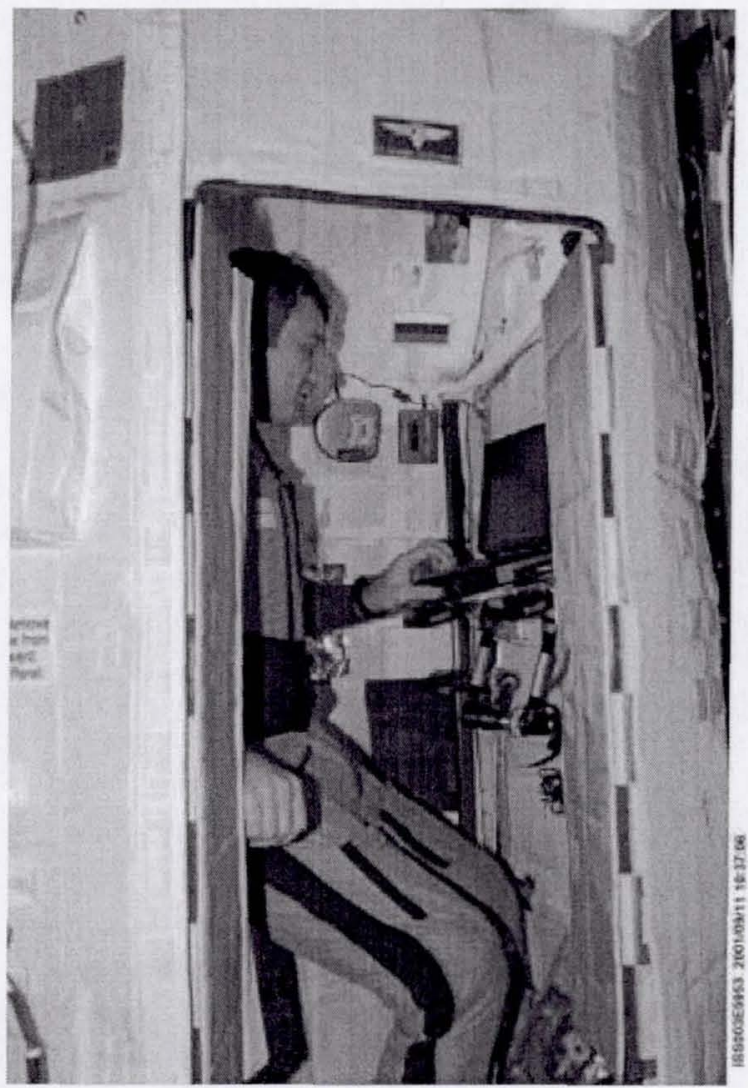

TeSS interior

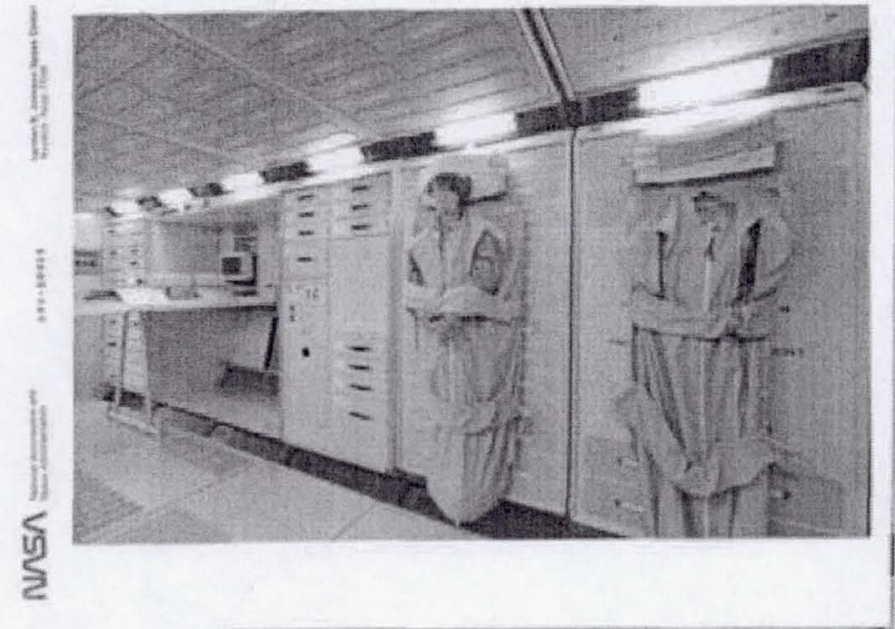

Mock up of improvised use of aisle for sleeping

Mock-ups were used to demonstrate the impact. Of sleeping in the aisle when the program began evaluating the delay of the U.S. Habitation module crew quarters. The program did not address the accommodations of visiting crew which have used the Lab module as their make shift crew quarters.

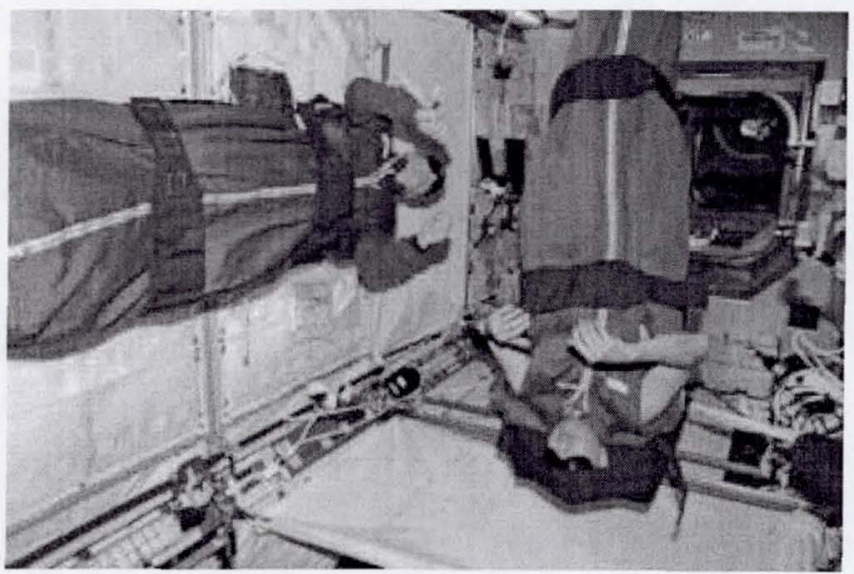

Crew sleeping in the Lab 


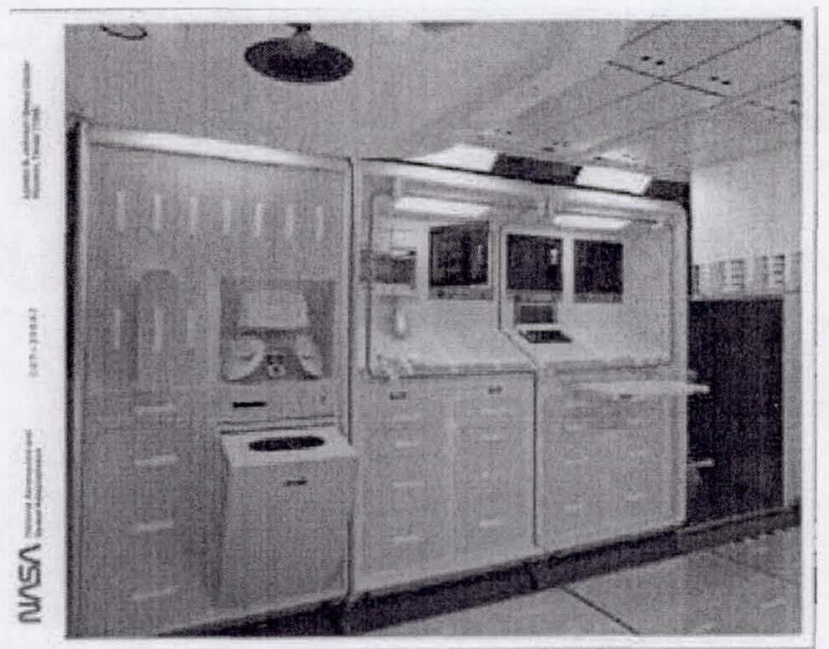

Interior mockup, the way the designers envisioned it

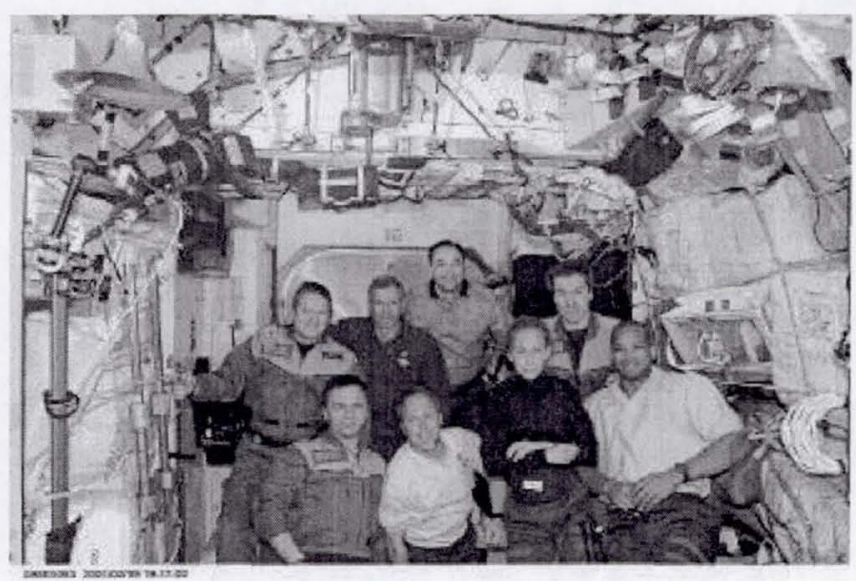

STS-98 and Expedition $1 \mathrm{crew}$ in Unity Node, note the significant amount of non standard stowage

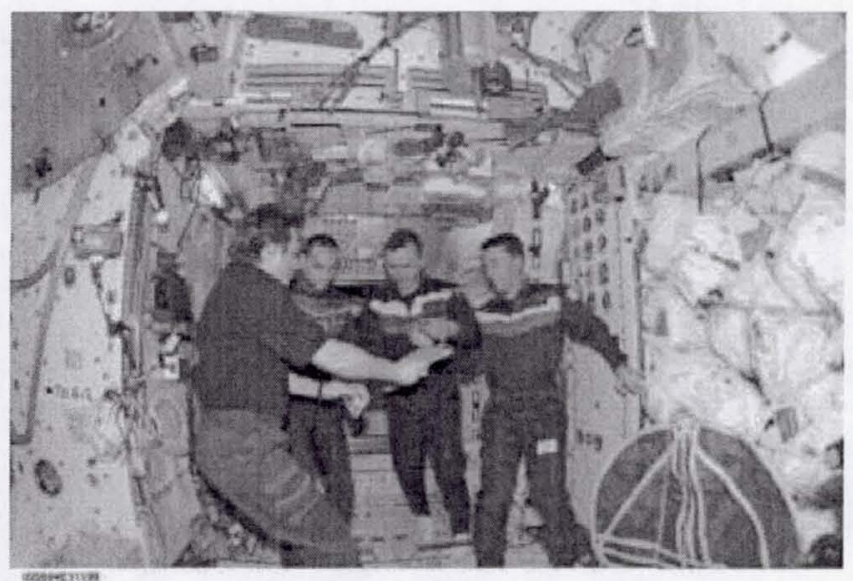

Visiting Crew in Unity Node, note stowage in radial port

The way the crew really lives

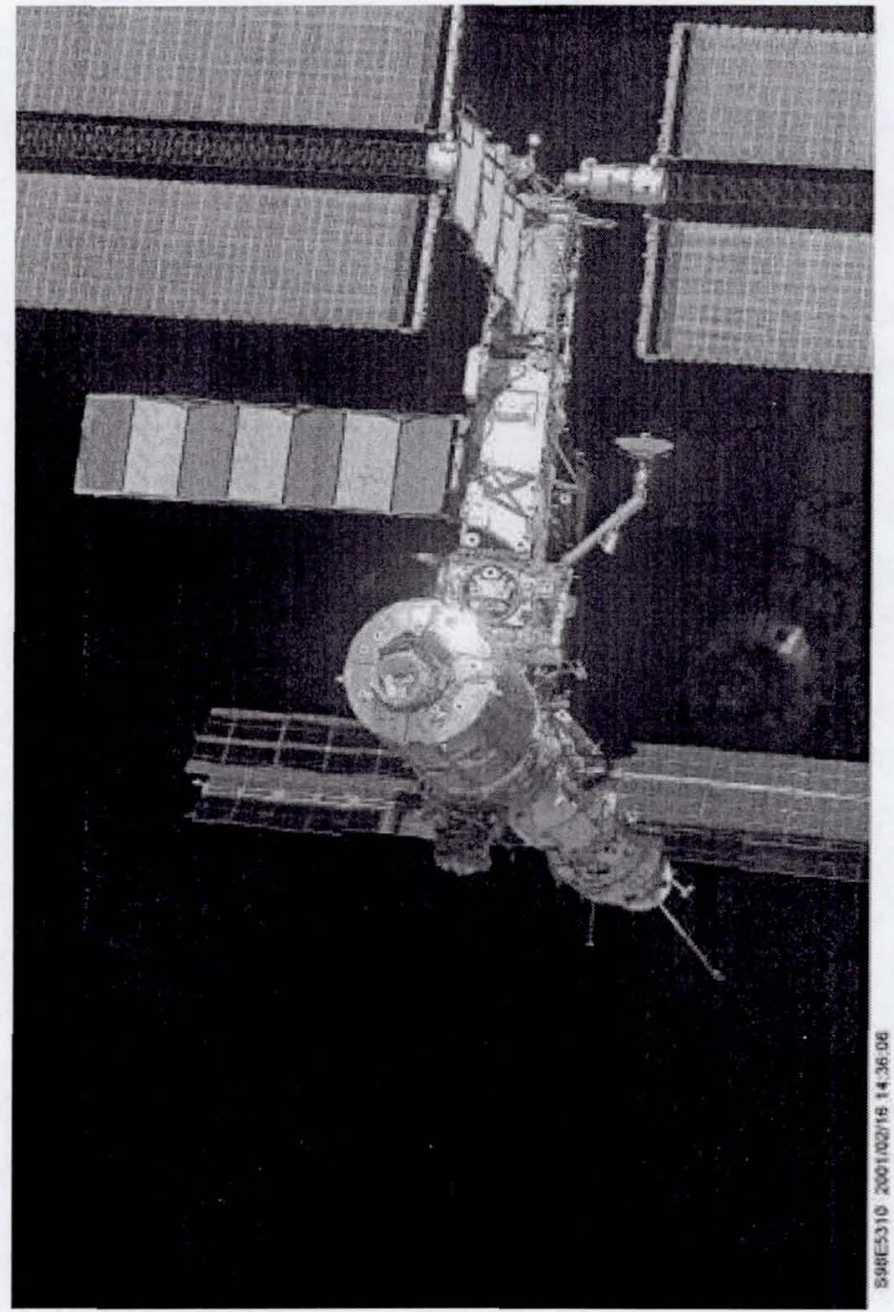

View of ISS with the Destiny module attached taken during STS-98 fly around

\section{CONCLUSION}

The US Segment of the ISS has benefited from the establishment and adherence to key fundamental architectural requirements. The architectural requirements adequately addressed hardware change aut, modularity and maintainability. These features will hopefully ensure the maintenance, operability of the hardware, and safe occupation of the Space Station for the next 20 plus years.

That said the aisle, the habitable volume, has not been protected or managed well. ISS operations are demonstrating that the original set of requirements and constraints on the vehicle's architecture are not adequate on their own to manage the on going changing environment. We failed to predict the impact and adequately provide the internal architectural features required to allow the crew to modify the environment for their day-to-day needs. 
We failed to establish the controls to manage the addition of new hardware requirements including temporary cabling, networks, payload design worksite set up and operations, and the impacts from visiting crew. Development of a full complement of planning and operations constraints and tools to track and manage the interior remains a work in progress as we gain more experience with living and working in the vehicle's defined architecture. The Space Station and future space programs will need to define the architectural and operational requirements and features to provide the designers, operators and inhabitants with these controls and tools.

\section{REFERNECES}

All images courtesy of NASA Digital Imagery Management System and photo library.

Space Station Interface Definition Document NSTS21000-IDD-ISS, (current revision) National Aeronautics and Space Administration, Lyndon B. Johnson Space Center, Houston, Texas,

\section{ACKNOWLEDGMENTS}

Don Magargee and the long list of individuals with design and human engineering expertise for their contributions to requirements, concepts and ideas that helped shape the current architecture of the ISS. David Fitts for his review and comments that helped improve the message of this writer.

\section{CONTACT INFORMATION}

Rod Jones, Deputy Manger of the International Space Station Mission Integration and Operations Mail Code OC, Johnson Space Center, Houston TX. 77058

William.r.jones1@jsc.nasa.gov

281-244-7941

\section{DEFINITIONS, ACRONYMS AND}

\section{ABREVIATIONS}

ISS: International Space Station

MPLM: Multi Purpose Logistics Module is used as the primary pressurized cargo carrier for the US Segment
RSR: Resupply Stowage Rack

RSP: Resupply Stowage Platform

STS: Space Transportation System

TeSS: Temporary Sleep Station

ZSR: Zero-g Stowage Rack 